\title{
Fatal fall from Height Cases in Shanghai, China, 2002-2011
}

\section{Bei-Xu Li"\#, Hui Li", Zheng Wang', Ai-Min Xue ${ }^{1 *}$}

${ }^{1}$ Department of Forensic Medicine, Fudan University, Shanghai, China

${ }^{2}$ Shanghai Research Institute of Criminal Science and Technology, Shanghai Public Security Bureau, Shanghai, China

"Authors have equally contributed to this work

\begin{abstract}
Death due to fall from height is a complex forensic issue. It could occur in suicide, accident or even homicide. Study of fall from height in China seems to be rare. In this study, 250 individuals died in fall from height cases in Shanghai were collected retrospectively from the files of SPSB from 2002 to 2011 . We evaluated the demographic data, the manner of death, forensic examination findings, and toxicological test results. Overall 250 individuals, 176 were male and 74 were female. 223 individuals were identified. Ages ranged from 1 year old to 86 year old. The average age was about $33.4 \pm 15.3$ years. The proportion of age from 18 to 29 was the highest. Among 223 identified individuals, 170 were Chinese and 53 were foreigners from 17 countries. Manner of death was mainly suicide $(46 \%, 115 / 250)$ and accident $(18 \%, 45 / 250)$, while the proportion of homicide was low $(3.6 \%, 9 / 250)$. The proportion of undetermined was high $(32.4 \%, 81 / 250)$. Forensic full autopsies were done in 87 cases. Ethanol and drugs detection were done in 118 individuals. Individuals' psychiatric history was not collected in the files. In conclusion, the characteristics of fall from height cases in Shanghai, China, are summarized to these: manner of death was mainly suicide and accident, low proportion of homicide, and high proportion of undetermined cases. Males were more than females. Individuals were mainly young adults. The injuries recorded in forensic examination files were common to occur in the exposing areas of body.
\end{abstract}

Keywords: Fall from height; Demographics; Manner of death; Forensic examination; Toxicological test

\section{Introduction}

Fall from height, which is predominantly an urban phenomenon, is a special type of mechanical injury. As economic growth and urbanization, the number of high-rise building in China gradually increased, especially in the coastal developed areas. Shanghai is one of the largest cities located in Yangtze River Delta in the East China. The general situation of fall from height cases in Shanghai inevitably attracts our attention. It could occur in suicide, accident or even homicide, so it is hard to determine manner of death. This retrospective study is based on the 250 individuals died in fall from height cases occurred in Shanghai, China from 2002 to 2011 to outline the basic characteristics of fall from height case in Shanghai and provide guidance for forensic working.

\section{Materials and Methods}

Shanghai Public Security Bureau (SPSB) and its branches are responsible for Shanghai's public security, crime control, and traffic administration. Most of fall from height cases, especially all the cases involving foreigners, were handled by SPSB. A small number of falls from height cases were examined by other organizations when homicides were ruled out. Additionally, full autopsy and toxicological test are not routine procedure in SPSB. Whether they will be done or not is dependent on the needs of cases. If death and scene investigation revealed no suspicious evidence and case was clear, no autopsy is performed, and the case will be closed by SPSB [1].

This study was a retrospective review of fall from height cases in SPSB over a 10 year period from 2002.1 to 2011.12. Cases were accepted for this study according to the following criteria: (1) corpses without death certificate were found in Shanghai, (2) corpse inspection was conducted by medical examiners in SPSB, (3) Cause of death was fall from height. A total of 250 cases met the study criteria. These archives were kept in SPSB record office.

Data was extracted from these cases' autopsy archives, initial investigation, and police reports in SPSB. These materials were reviewed and analyzed as to (1) demographic data of the decedents, such as age and gender, (2) manner of death, (3) forensic examination findings, (4) toxicological test results. Two reviewers independently extracted data from each of the archives. Disagreements between reviewers were resolved through discussions and a final consensus.

The data were presented as means-standard errors (SE) for age. Statistical analysis was given using the related programs in Microsoft Excel 2013. This retrospective study was based on the forensic autopsy cases archives. It was approved by both Shanghai Public Security Bureau Ethics Committee and Fudan University Ethics Committee. The written informed consent was given by decedent's next of kin, who was told that the investigation information might be used in the scientific research when the autopsy was taken. All the archives were anonymized and deidentified prior to analysis.

\section{Results}

\section{Demographics}

According the archives of SPSB, in this decade, the number of fall from height decedents was 250, 223 of whom were identified. In all the individuals, 176 were male and 74 were female. Male/Female ratio was about 2.38:1. The age of 223 identified individuals ranged from 1 yearold to 86 year old. Most of them were young adults. The average age was about $33.4 \pm 15.3$ years. Individuals in 18 to 29 year old group were the most. 170 Chinese and 53 foreigners from 17 countries composed the identified 223 individuals. The distribution of foreign individuals' nationality is showed in Figure 1 and Table 1.

*Corresponding author: Ai-Min Xue, department of forensic medicine, Fudan University, Shanghai, China, Tel: +86-21-54237402; Fax: +86-21-54237668; E-mail: fdxueaimin@163.com

Received August 08, 2017; Accepted September 01, 2017; Published September 08, 2017

Citation: Li BX, Li H, Wang Z, Xue AM (2017) Fatal fall from Height Cases in Shanghai, China, 2002-2011. J Forensic Med 2: 120. doi: 10.4172/24721026.1000120

Copyright: @ 2017 Li BX, et al. This is an open-access article distributed under the terms of the Creative Commons Attribution License, which permits unrestricted use, distribution, and reproduction in any medium, provided the original author and source are credited. 
Citation: Li BX, Li H, Wang Z, Xue AM (2017) Fatal fall from Height Cases in Shanghai, China, 2002-2011. J Forensic Med 2: 120. doi: 10.4172/24721026.1000120

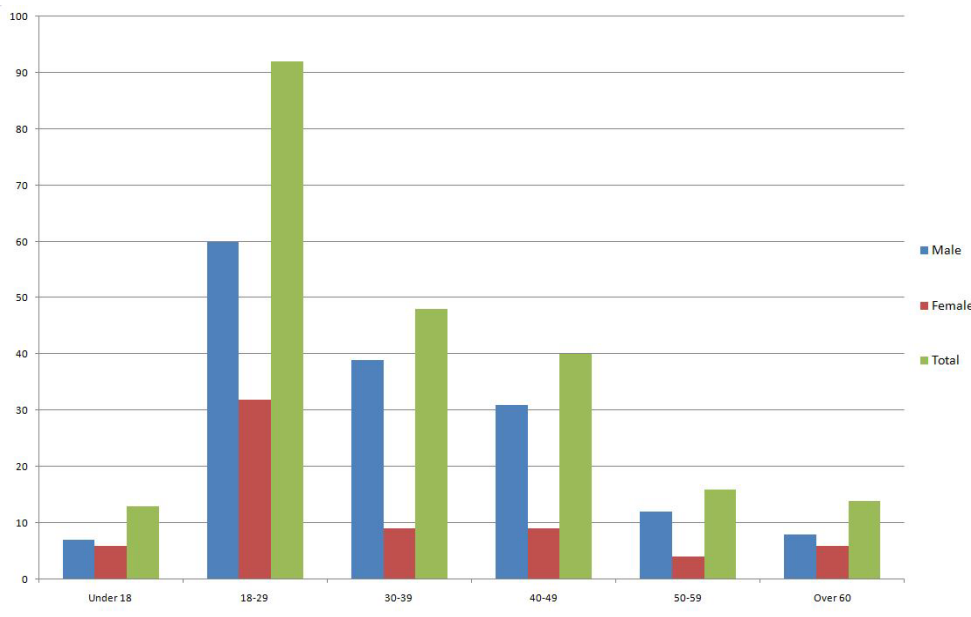

Figure 1: Distribution of numbers of individuals in different age ranges.

\begin{tabular}{|c|c|c|}
\hline Nationality & N & $\%$ \\
\hline Japan & 16 & 30.2 \\
\hline America & 8 & 15.1 \\
\hline Korea & 4 & 7.5 \\
\hline German & 4 & 7.5 \\
\hline Britain & 3 & 5.6 \\
\hline Singapore & 3 & 5.6 \\
\hline Russia & 2 & 3.8 \\
\hline Canada & 2 & 3.8 \\
\hline Philippines & 2 & 3.8 \\
\hline Slovakia & 2 & 3.8 \\
\hline others & 7 & 13.2 \\
\hline
\end{tabular}

Table 1: Distribution of foreign individuals' nationality others including Australia, France, Denmark, Italy, Mexico, Columbia, India (one victim per nation).

\begin{tabular}{|c|c|c|c|c|c|}
\hline Year & Accidental & Suicide & Homicide & Undetermined & Total \\
\hline 2002 & 1 & 5 & 1 & 2 & 9 \\
\hline 2003 & 5 & 6 & 0 & 3 & 14 \\
\hline 2004 & 4 & 12 & 1 & 10 & 27 \\
\hline 2005 & 5 & 14 & 1 & 5 & 25 \\
\hline 2006 & 4 & 14 & 1 & 8 & 27 \\
\hline 2007 & 2 & 9 & 0 & 9 & 20 \\
\hline 2008 & 7 & 9 & 0 & 15 & 31 \\
\hline 2009 & 4 & 19 & 0 & 6 & 29 \\
\hline 2010 & 4 & 12 & 4 & 14 & 34 \\
\hline 2011 & 9 & 15 & 1 & 9 & 34 \\
\hline Total & 45 & 105 & 9 & 81 & 250 \\
\hline
\end{tabular}

Table 2: Distribution of the number of victims by year and by manner of death.

\section{Manner of death}

115 suicides, 45 accidents, 9 homicides and 81 undetermined composed the 250 cases (Table 2 and Figure 2).

\section{Forensic examination findings}

Forensic examination showed that among all 250 individuals, fracture occurred in 236 of them (94.4\%). Multiple fractures occurred in 198 cases, accounting for $79.2 \%$ individuals. Fracture occurred commonly in the ribs, cranium and long bones which hit the ground first. Distribution of bone fracture was shown in Table 3.

External inspection was conducted in 244 individuals. According

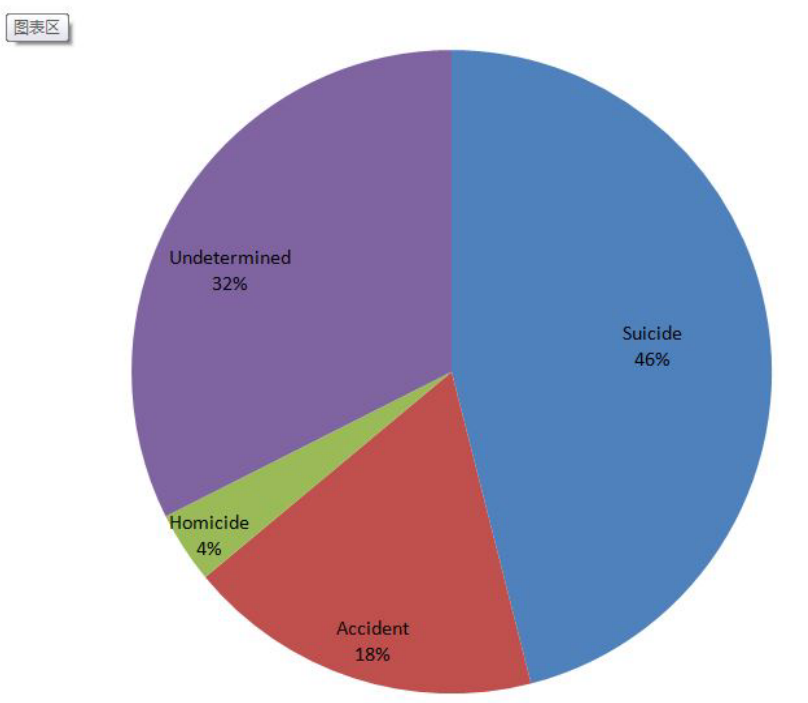

Figure 2: Distribution of numbers of individuals by manner of death.

\begin{tabular}{|c|c|c|}
\hline Fracture bone & $\mathbf{n}$ & $\%$ \\
\hline Rib & 162 & 64.8 \\
\hline Lower limb & 141 & 56.4 \\
\hline Cranium & 130 & 52 \\
\hline Upper limb & 121 & 48.4 \\
\hline Jaw & 59 & 23.6 \\
\hline Pelvis & 57 & 22.8 \\
\hline Vertebra & 50 & 20 \\
\hline Sternum & 41 & 16.4 \\
\hline *Basis cranii & 34 & 39.1 \\
\hline
\end{tabular}

All the incidences except basis crania fracture were calculated by total 250 cases The incidence of basis crania fracture was calculated by 87 cases which autopsies were done

Table 3: Distribution of fracture by bone.

to external inspection, the external injuries were mainly abrasion and contusion which are common to occur in the exposing areas of body such as head and face, trunk, limbs. Distribution of external injuries was shown in table. Forensic full autopsy was done in 87 individuals. 
All the 87 individuals had visceral injury. Substantive viscera such as lung, liver and spleen were more vulnerable. Distribution of visceral injuries was shown in Tables 4 and 5.

\section{Toxicological test}

Ethanol and drugs detection were done in 118 individuals. Heart blood, urine and gastric content were collected. Heart blood was collected in 104 individuals. While urine and gastric content were collected in 29 individuals and 31 individuals respectively. The number of positive cases was 35 , of which 21 were positive for ethanol only, 4 were positive for both alcohol and drugs, 10 were positive for drugs only. The positive rate of ethanol or drugs was $29.7 \%$. There were two cases that heart blood alcohol content $(99.78 \mathrm{mmol} / 1,88.91 \mathrm{mmol} / \mathrm{l})$ had reached the lethal dose $(87 \sim 109 \mathrm{mmol} / \mathrm{l})$ by quantitative test.

\section{Discussion}

The yearly number of fatal fall from height cases shows a fluctuating rising trend from 2002 to 2011 , in both male and female. The real estate booming, the influx of migrants and yearly increased population may account for it (Figure 3).

\begin{tabular}{|c|c|c|}
\hline & $\mathbf{n}$ & $\%$ \\
\hline Limbs & 236 & 96.7 \\
\hline Head and face & 222 & 91.8 \\
\hline Trunk & 221 & 90.6 \\
\hline Neck & 80 & 31.8 \\
\hline Perineum & 20 & 8.2 \\
\hline
\end{tabular}

The incidences of external injuries were calculated by 244 cases which external examination results were recorded in the files of SPSB

Table 4: Distribution of external injuries.

\begin{tabular}{|c|c|c|}
\hline & $\mathbf{n}$ & $\%$ \\
\hline Lung & 46 & 52.9 \\
\hline Liver & 37 & 42.5 \\
\hline Spleen & 23 & 26.4 \\
\hline Heart & 19 & 21.8 \\
\hline Kidney & 9 & 10.3 \\
\hline Gut & 3 & 3.4 \\
\hline
\end{tabular}

The incidences of external injuries were calculated by 87 cases which autopsies were done
Male were far more than female in fall from height cases, with the male/female ratio 2.38:1 (176:74). Further, the male/female ratios in different manner of death were analyzed. In accidents, $82.2 \%$ deaths were male and male/female ratio was 4.63:1 (37:8). In suicides, $63.5 \%$ deaths were male and male/female ratio was 1.74:1 (73:42). In homicides, $55.6 \%$ deaths were males and male/female ratio was $1.25: 1$ (5:4). This finding was somehow different from previous study, because Goren et al reported that females were more than males in suicides [2]. However, women were more inclined to use other way such as taking poison to suicide [3]. The male/female ratio in accidents was high. The real estate booming in this decade not only created a lot of outdoor construction work opportunities, but also attracted a lot of migrant workers swarming into Shanghai. These contributed to the increase of male accidental fall (Figure 4 and Table 6).

Most individuals were young and middle-aged adults, and individuals in 18 to 29 year old group were the most. People at this age were facing more stress from emotion, work and society, which may cause suicide. Meanwhile, the outdoor construction workers are nearly all young men, which made them easier to suffer an accident (Figure 1).

The proportions of homicide and suicide in under 18 year old are higher than others. Though homicide rate was low $(4.0 \%, 9 / 223)$, that was obviously higher in under 18 year-old group $(23.1 \%, 3 / 13)$. Two infanticides accounted for it. On the other hand, accident rate $(30.8 \%$, $4 / 13)$ was also higher than the overall $(18.8 \%, 42 / 223)$. These findings were similar to the previous reports $[2,4]$. The proportion of foreign individuals was high. In our opinion, two reasons may play a significant role in this result. Firstly, Shanghai is an international metropolis and the foreign population in Shanghai is relatively high (170000). Secondly, all cases involving foreigners were handled by SPSB while part of Chinese fall from height cases were handled by other organizations. Furthermore, the proportion of Japanese individuals was pretty high $(16 / 53)$ and 7 individuals were committed suicide. Japanese seems to be

\begin{tabular}{|c|c|c|c|c|c|}
\hline & Male & & Female & & Gender ratio \\
\hline Suicide & 73 & $63.50 \%$ & 42 & $36.50 \%$ & $1.74: 1$ \\
\hline Accident & 37 & $82.20 \%$ & 8 & $17.80 \%$ & $4.63: 1$ \\
\hline Homicide & 5 & $55.60 \%$ & 4 & $44.40 \%$ & $1.25: 1$ \\
\hline Undetermined & 61 & $75.30 \%$ & 20 & $24.70 \%$ & $3.05: 1$ \\
\hline Total & 176 & $70.40 \%$ & 74 & $29.60 \%$ & $2.38: 1$ \\
\hline
\end{tabular}

Table 6: Distribution of manner of death by gender.






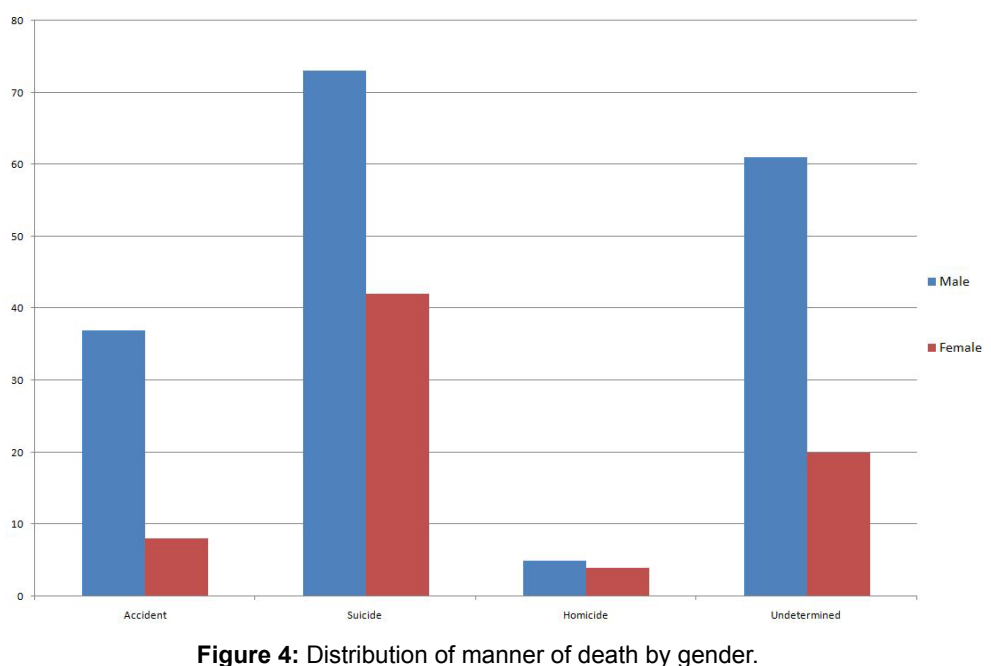

Figure 4: Distribution of manner of death by gender.



Figure 5: Distribution of manners of death in different age ranges.

more likely to commit suicide when they had stress in work or life $[5,6]$. According to the data from Japanese consulate, the Japanese population in Shanghai was relatively high (47700, as of 2013 October), which can also be the reason for the result (Table 7 and Figure 5).

In the present study, injuries caused by fall from height included fractures, external injuries, visceral injuries. According to the file records, the incidence of fracture was pretty high (94.4\%) and multiple fracture was common (79.2\%). Fractures occurred commonly in the ribs, cranium and long bones which hit the ground first. The external injuries were mainly abrasion and contusion which are common to occur in the exposing areas of body such as head and face, trunk, limbs. Whereas in the cover areas of body such as perineum, fewer external injuries were found. Autopsy records showed that substantive viscera such as lung, liver and spleen were vulnerable. These data were line with the literature [2]. It is demonstrated that injuries caused by fall from height were extensive and complex, throughout the whole body surface and viscera. While multiple fractures and injuries were common. Injuries of fall from height were associated with several factors such as height of fall, weight of body, velocity of fall and point of impact. Basically, the higher the falling height is, the greater the kinetic energy will be transformed, and the more serious the injuries will be. Sometimes under exceptional

\begin{tabular}{|c|c|c|c|c|c|c|c|}
\hline & Under 18 & $\mathbf{1 8 - 2 9}$ & $\mathbf{3 0 - 3 9}$ & $\mathbf{4 0 - 4 9}$ & $\mathbf{5 0 - 5 9}$ & Over 60 & Total \\
\hline Suicide & 2 & 48 & 23 & 18 & 10 & 6 & 107 \\
\hline Accident & 4 & 19 & 5 & 9 & 3 & 2 & 42 \\
\hline Homicide & 3 & 1 & 1 & 1 & 1 & 2 & 9 \\
\hline Undetermined & 4 & 24 & 12 & 12 & 2 & 4 & 65 \\
\hline Total & 13 & 92 & 48 & 40 & 16 & 14 & 223 \\
\hline
\end{tabular}

Table 7: Distribution of manner of death in different age ranges (223 identified individuals).

circumstances even if the fall height is very low, the injuries were still serious. Wang et al reported a case that the falling height is just $8.2 \mathrm{ft}$, but because victim's face impacted the corner of the chair, fatal basal fractures and face perforating injuries occurred [7].

Toxicological test can give valuable information to determine manner of death. Previous study suggested that ethanol and drugs are important factors in sudden unexpected death investigation [8]. When fall from height cases were not clear and the investigators of SPSB filed applications, a thorough and comprehensive toxicology test would be done to analyze the cases. In the present study, ethanol and drugs detection were done in 118 individuals. There were 25 individuals positive for ethanol ( 21 were positive for ethanol only, 4 were positive 
for both ethanol and drugs). Among the 25 alcohol positive cases, the manner of death in 20 cases was determined. The accident rate was $25 \%(5 / 20)$, which was higher than the total accident rate (18\%). This statistical result is consistent with previous study [9]. The positive rate in drug detection $(11.9 \%, 14 / 118)$ is low. Frost et al reported that in their study, $12 \%$ were positive for ethanol only, $44 \%$ were positive for drugs only and $15 \%$ were positive for both alcohol and drugs [9]. It means the proportion of individuals with drug use in fatal fall from height cases in Shanghai seemed to be lower. The frequently detected drugs were benzodiazepines and opioids, which is similar to the previous study [9].

Fall from height is a complex forensic issue. According to the previous reports, fall from height cases often occur in accidents and suicides. Occasionally it could also be the result of homicides. It is hard to determine manner of death in a fall from height case without witness evidence. Manner of death is the key point in a fall from height case investigation. It is important to considerate comprehensively. However, there were some limitations in this study. One third of fall from height cases' manner of death was unknown. As a large proportion of decedents were migrants, their medical, psychiatric and social history was missed. Even they cannot be identified. People with psychiatric history are more likely to attempt suicide [10-13]. Unfortunately, psychiatric history records were not collected in the files of SPSB. The decedents' psychiatric status was unknown.

Additionally, analyzing the distance of the body from the site of descent sometime may help us determine the manner of death. The distance of the body from the site of descent includes the falling height and the horizontal distance. According Mao et al and Goren et al reports, the falling height in suicide was statistically higher than that in accident $[2,14]$. For similar heights, Wischhusen et al have demonstrated that in passive falls, the horizontal distance is usually farther than jumps [15]. It is a pity that the horizontal distance and the falling height in the cases of our study were not recorded by SPSB. Measurement data cannot be compared with previous reports.

\section{Conclusion}

In conclusion, death due to fall from height is a complex forensic issue. Not only forensic examinations, but also the scene investigation and the medical, psychiatric and social history of the individual should be taken into consideration. Based on the available data, the characteristics of fall from height cases in Shanghai, China, are summarized to these: manner of death was mainly suicide. Males were more than females. Individuals were mainly young adults. The injuries recorded in forensic examination files were common to occur in the exposing areas of body. On condition that data were in more detail (psychiatric history records, the falling height and the horizontal distance), further researches should be done to complement our study and provide guidance for forensic working in the future.

\section{References}

1. He M, Li WC, Sun DM, Ma KJ, Zhao ZQ, et al. (2014) Epitome of China's unnatural deaths: A historically retrospective study of forensic autopsy cases in Shanghai Public Security Bureau from 1990 to 1999. Am J Forensic Med Pathol 35: 218-221.

2. Goren S, Subasi M, Tyrasci Y, Gurkan F (2003) Fatal falls from heights in and around Diyarbakir, Turkey. Forensic Sci Int 137: 37-40.

3. Callanan VJ, Davis MS (2012) Gender differences in suicide methods. Soc Psychiatry Psychiatr Epidemiol 47: 857-869.

4. Gill JR (2001) Fatal descent from height in New York city. J Forensic Sci 46: 1132-1137.

5. Inoue K, Nishimura Y, Okazazi Y, Fukunaga T (2014) Discussion based on analysis of the suicide rate and the average disposable income per household in Japan. West Indian Med J 63: 344-347.

6. Takeshima T, Yamauchi T, Inagaki M, Kodaka M, Matsumoto T, et al. (2015) Suicide prevention strategies in Japan: A 15 year review (1998-2013). J Public Health Pol 36: 52-66.

7. Wang Q, Ishikawa $T$, Michiue $T$, Maeda $H$ (2010) Fatal facial-intracranial impalement injury in an accidental fall from a height: An autopsy case report with a review of the literature. Forensic Sci Int 200: e21-24.

8. Ehmke U, Toit-Prinsloo LD, Saayman G (2014) A retrospective analysis of alcohol in medico-legal autopsied deaths in Pretoria over a 1 year period. Forensic Sci Int 245C: 7-11.

9. Frost J, Slordal L, Vege A, Nordrum IS (2012) Forensic autopsies in a naturalistic setting in Norway: Autopsy rates and toxicological findings. Forensic Sci Int 223: 353-358.

10. Chang B, Gitlin D, Patel R (2011) The depressed patient and suicidal patien in the emergency department: evidence-based management and treatment strategies. Emerg Med Pract 13: 1-23.

11. Choi NG, DiNitto DM, Marti CN (2014) Middle-aged and older adults who had serious suicidal thoughts: who made suicide plans and non-fatal suicide attempts? Int Psychogeriatr, pp: 1-10.

12. Qin P, Agerbo E, Mortensen PB (2003) Suicide risk in relation to socioeconomic, demographic, psychiatric, and familial factors: A national register-based study of all suicides in Denmark, 1981-1997. Am J Psychiatry 160: 765-772.

13. Ranjan R, Kumar S, Pattanayak RD, Dhawan A, Sagar R (2014) (De-) criminalization of attempted suicide in India: A review. Ind Psychiatry J 23: 4-9.

14. Mao SW, Liu XJ, Su CP, Zhang M, Mu ZQ, et al. (2009) Analysis of 574 cases of high-fall death. Fa Yi Xue Za Zhi 25: 276-278.

15. Wischhusen F, Patra S, Braumann M, Turk EE, Puschel K (2006) Analysis of jumping/falling distance from a height. Forensic Sci Int 156: 150-153. 